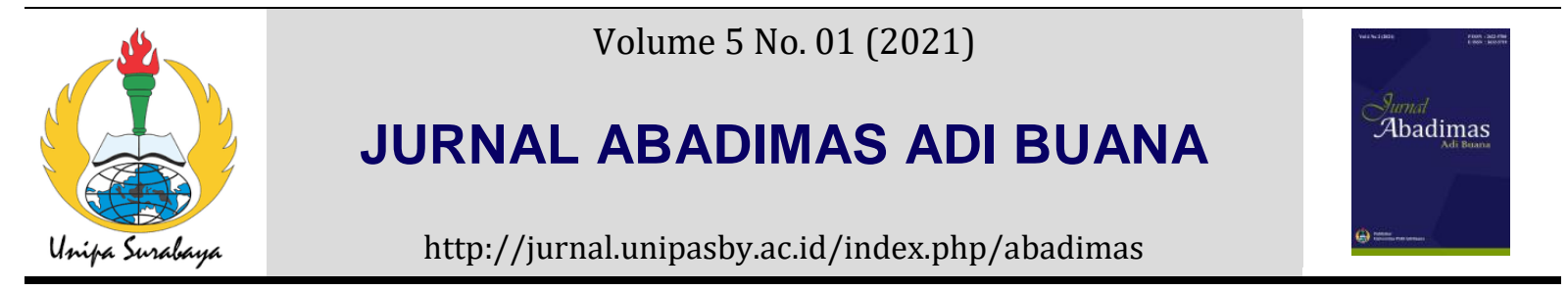

\title{
PENDAMPINGAN GURU MENGEMBANGKAN ASSESMENT KOMPETENSI MINIMUM (AKM) BERORIENTASI PISA UNTUK MENINGKATKAN KUALITAS HASIL PEMBELAJARAN DI SEKOLAH DASAR WILAYAH KABUPATEN BOGOR
}

\author{
Uswatun Hasanah ${ }^{1 *}$, Edwita $^{1}$, Ahmad Januar ${ }^{2}$ \\ ${ }^{1}$ Program Studi PGSD, Universitas Negeri Jakarta, Jakarta, Indonesia \\ ${ }^{2}$ SDN Cipulir 11 Pagi, Jakarta, Indonesia \\ *Email: uswatunhasanah@unj.ac.id
}

\begin{abstract}
Informasi Artikel Abstrak

Kata kunci:

Assessment kompetensi minimum, PISA,

Penilaian, Pembelajaran

Diterima: 21-05-2021

Disetujui: 07-06-2021

Dipubikasikan: 14-07-

2021

Asessmen kompetensi minimum merupakan jenis penilaian yang dapat mengukur kemampuan pemecahan masalah siswa dengan menggunakan literasi membaca dan literasi numerasi yang dimiliki. Adapun konteks literasi yang dituju berorientasi pada PISA (Programme for International Student Assessment). Kegiatan pengabdian ini bertujuan untuk meningkatkan kapasitas guru dalam mengembangkan assessment kompetensi minimum berorientasi PISA untuk meningkatkan kualitas pembelajaran. Peserta kegiatan terdiri dari 107 guru yang tersebar di wilayah Kabupaten Bogor. Kegiatan ini dilakukan secara daring menggunakan aplikasi zoom meeting. Hasil pengabdian menunjukkan bahwa $72,9 \%$ guru pada kategori "Baik" dalam memahami hakikat assessment kompetensi minimum, komponen assessment sampai pada pengembangan instrument penilaian kompetensi minimm berorientasi PISA. Dengan adanya kegiatan pengabdian ini, diharapkan guru dapat mengembangkan penilaian pembelajaran secara tepat sasaran sehingga dapat meningkatkan kualitas hasil pembelajaran
\end{abstract}

\section{Keywords :}

Minimum Competency

Assessment, PISA,

Assessment, Learning 


\section{PENDAHULUAN}

Seiring berkembangnya teknologi ini juga membuat tantangan hidup menjadi kian berat. Kehidupan di era globalisasi ini menuntut kita untuk memiliki berbagai kemampuan agar mampu bersaing di era globalisasi saat ini. Berbagai kemampuan tersebut dirangkum dalam keterampilan abad-21. Beberapa hasil penelitian menunjukkan bahwa keterampilan yang harus dimiliki seseorang untuk menghadapi kehidupan, dunia kerja di abad ke-21 adalah sebagai berikut: (1) kemampuan berpikir kritis dan pemecahan masalah, (2) kolaborasi dan kepemimpinan, (3) ketangkasan dan kemampuan beradaptasi, (4) inisiatif dan berjiwa entrepeneur, (5) mampu berkomunikasi efektif baik secara oral maupun tertulis, (6) mampu mengakses dan menganalisis informasi, dan (7) memiliki rasa ingin tahu dan imajinasi (Lebrun, 2017; Quint \& Condliffe, 2018; Steele et al., 2019; Widana, 2017). Disinilah pentingnya peran pendidikan. Pendidikan dewasa ini tidak hanya dituntut untuk menghasilkan Sumber Daya Manusia (SDM) dengan pengetahuan yang memadai namun juga SDM yang memiliki tujuh keterampilan diatas agar kelak SDM ini mampu bersaing secara global.

Hal itulah yang mendorong pemerintah kembali membuat kebijakan baru berupa penghapusan Ujian Nasional (UN) dan menggantinya menjadi asessmen kompetensi minimum (AKM) mulai tahun 2021 mendatang. Asessmen kompetensi minimum (AKM) merupakan asesmen yang mengukur kemampuan minimal yang dibutuhkan siswa untuk dapat belajar dan merupakan bentuk penyederhanaan dari Ujian Nasional yang begitu kompleks. Adapun materinya hanya terdiri atas tiga yaitu bahasa (literasi), matematika (numerasi), dan penguatan pendidikan karakter (Kaj, 2020; Penelitian et al., 2013). Adapun materi bahasa (literasi) dan matematika (numerasi) pada soal Asessmen kompetensi minimum (AKM) mengacu pada PISA. PISA (Programme for International Student Assessment) merupakan studi internasional yang mengukur kompetensi siswa dalam bidang literasi membaca dan matematika. Tes yang diselenggarakan oleh Organisasi Kerja Sama dan Pembangunan Ekonomi (OECD) ini diikuti oleh 79 negara, dari negara maju dan berkembang. Model soal tesnya sama untuk setiap negara peserta. Soal-soal ini diterjemahkan ke bahasa masing-masing negara (Baldi et al., 2007). Adapun tes ini tidak bertujuan untuk menilai penguasaan siswa akan konten kurikulum, melainkan untuk mempelajari apakah siswa dapat mengaplikasikan pengetahuan yang telah dipelajari dalam situasi yang ditemui dalam kehidupan sehari-hari (Pratiwi, 2019). Penilaian PISA tidak terbatas dengan kognitif level ingatan dan pemahaman saja melainkan sudah pada level menerapkan dan menganalisis. Dalam literasi membaca, jenis soal-soalnya mengharapkan siswa dapat menentukan ide utama dalam teks, mencari hubungan berbagai informasi dalam teks, dan menentukan kesimpulan sederhana dari teks bacaan. Adapun dalam literasi matematika, jenis soalnya tidak sekedar paham tentang matematika akan tetapi juga mampu mengunakannya dalam pemecahan masalah sehari-hari (OECD, 2019).

Di Indonesia, penerapan system Asessmen kompetensi minimum (AKM) sudah dimulai sejak tahun 2020. Hal ini bertujuan untuk: (1) memberikan waktu bagi sekolah dan para guru untuk 
melakukan perbaikan sebelum anak lulus, dan (2) agar tidak bisa dijadikan sebagai alat seleksi untuk siswa yang akan menimbulkan stress bagi anak-anak dan orangtua (Kaj, 2020). Mengingat Asessmen kompetensi minimum ini merupakan salah satu upaya pemerintah selaku pembuat kebijakan untuk meningkatkan kemampuan literasi membaca dan numerasi siswa, soal-soal jenis ini ini haruslah memenuhi domain literasi membaca dan numerasi yang sebagaimana telah dikemukakan PISA.

Namun pada kenyataannya, sebagian besar guru belum menerapkan penilaian tersebut secara optimal. Hal ini dikarenakan keterbatasan mereka terhadap konsep assessment kompetensi minimum dan literasi dalam penilaian pembelajaran. Alhasil, kenyataan yang terjadi pelaksanaan assessment kompetensi minimum tidak berjalan secara optimal. Banyak keluhan dari para guru dengan keberlangsungan program ini. Salah satunya terjadi di beberapa sekolah dasar sekitar Kabupaten Bogor. Berdasarkan observasi pra lapangan, guru merasa sulit dalam mengembangkan penilaian berbasis Asessmen kompetensi minimum (AKM). Mereka berpendapat membuat soalnya saja membutuhkan daya nalar yang rumit. Padahal Dinas Pendidikan setempat telah mengadakan pelatihan kepada para guru dalam hal penilaian berbasis Asessmen kompetensi minimum (AKM). Namun yang terjadi lapangan, sebagian besar guru belum menguasai jenis penilaian tersebut. Akibatnya penilaian menjadi beban guru sehingga dikerjakan secara terpaksa dan berdampak negatif pada kualitas pembelajaran yang dilakukan.

Hakikatnya, pembelajaran dapat berhasil dan bermakna jika proses yang dilalui melalui suatu aktivitas yang bermakna pula. Guru perlu memiliki kemampuan dalam menilai hasil belajar siswa untuk menciptakan kualitas hasil pembelajaran yang optimal. Dalam menilai hasil belajar harus mencakup berbagai aspek yang dapat menggambarkan perkembangan atau perubahan tingkah laku pada siswa dan tidak hanya dilakukan untuk memberikan hasil berupa angka. Dengan menerapkan penilaian berbasis assessment kompetensi minimum, hasil yang ditunjukkan pun akan lebih valid dan objektif. Penilaian kompetensi minimum termasuk jenis penilaian autentik dalam pembelajaran. Authentic assessments are function-based and based in a child's routines, as opposed to the abovedescribed conventional assessments, which are the typical norm-referenced assessments (de Sam Lazaro, 2017). Sesuai dengan peryataan di atas bahwa penilaian autentik sangat berbeda dengan penilaian konvensional pada umumnya yang hanya mengandalkan pada angka. Penilaian autentik merupakan salah satu bentuk penilaian hasil belajar peserta didik yang didasarkan atas kemampuannya menerapkan ilmu pengetahuan yang dimiliki dalam kehidupan yang nyata di sekitarnya (Ermawati, Siti., \& Hidayat, 2017). Pernyataan tersebut menunjukkan bahwa dalam penilaian autentik, peserta didik dilibatkan secara aktif dan realistis dalam mengevaluasi kemampuan mereka sendiri.

Hasil penelitian yang telah dilakukan oleh peneliti sebelumnya tentang penialaian autentik antara lain (Kartowagiran \& Jaedun, 2016), (Fitriani, 2017), (de Sam Lazaro, 2017) (Noor et al., 2016), (Alfian et al., 2015), (Hodgman, 2014), (Azim \& Khan, 2012), (James \& Casidy, 2018), (Susani, 
2018), (Larkin, 2014), (Villarroel et al., 2017), (Wiggins, 1990), (Charoenchai et al., 2015), dan (Holliday et al., 2015). Asesment Kompetensi Minimum termasuk jenis penilaian autentik karena assessment kompetensi minimum (AKM) menyajikan masalah-masalah dengan beragam konteks yang diharapkan mampu diselesaikan oleh murid menggunakan kompetensi literasi membaca dan numerasi yang dimilikinya. assessment kompetensi minimum (AKM) dimaksudkan untuk mengukur kompetensi secara mendalam, tidak sekedar penguasaan konten.

Berdasarkan uraian di atas, maka sangat perlu dilakukan pendamingan guru dalam mengembangkan Assesment Kompetensi Minimum (AKM) Kegiatan ini sangat penting karena berdampak positif dalam mengembangkan kualitas hasil pembelajaran siswa. Dengan adanya pendampingan ini, guru dapat dilatih untuk mengolah system penilaian pembelajaran sehingga hasil penilaian yang dilakukan dapat mencerminkan seluruh aspek perkembangan siswa.

\section{METODE}

Metode pelaksanaan kegiatan pengabdian ini adalah prospektif observasional deskriptif, dimana subjek diukur dalam rentang waktu antara 17 - 19 Februari 2021. Sasaran kegiatan pengabdian ini adalah 107 guru yang tersebar di wilayah kabupaten Bogor dengan teknik pengambilan sampel adalah purposive sample. Kegiatan pengabdian ini dilaksanakan dengan melalui 3 tahap yaitu perencanaan, implementasi, refleksi dan evaluasi. Pada tahap perencanaan, tim pengusul membuat perencanaan untuk kegiatan pengabdian masyarakat, diantaranya membuat jadwal kegiatan, menentukan sekolah sebagai obyek pengabdian, menyusun materi pelatihan untuk guru-guru, menyusun kegiatan yang akan dilakukan guruguru disertai perangkat-perangkat instrumen yang diperlukan. Di samping itu pada tahap perencanaan, pengusul bersama tim mengadakan survei mengunjungi lokasi sekolah dasar. Kemudian kami melakukan observasi pembelajaran yang dilakukan oleh guru-guru di sekolah tersebut. Pada tahap ini, tim mencatat apa saja yang menjadi kelemahan dan mengidentifikasi permasalahan mitra.

Adapun pada tahap pelaksanaan, tim pengusul melaksanakan pendampingan bagi guruguru secara daring dengan zoom untuk mengadakan pelatihan penerapan Asessment kompetensi minimum selama 3 hari.

Rincian kegiatannya adalah sebagai berikut:

1) Hari ke-1: Penanaman Konsep

a) Pemberian Pretest terkait Assesment Kompetensi Minimum

b) Pemberian pemahaman tentang konsep dan prinsip Asessment Kompetensi Minimum 
c) Pemberian pemahaman tentang teknik dan instrument Asessment Kompetensi Minimum

2) Hari ke-2: Implementasi

Setiap individu mengembangkan penilaian kompetensi minimum di bawah bimbingan tim pengusul. Pendampingan difokuskan pada penerapan Asessment kompetensi minimum pada siswa dan refleksi penilaian pembelajaran.

3) Hari ke- 3: Evaluasi dan Refleksi

a) Pemberian posttest terkait assesment kompetensi minimum

b) Refleksi diri

Adapun pada tahap refleksi dilakukan dengan strategi: (1) guru penyaji menyampaikan penilaian diri terhadap pengembangan instrument penilaian asessment kompetensi minimum yang baru dilaksanakan, dan para observer menyampaikan hasil pengamatan tentang aktivitas siswa dalam bentuk penyampaian data interpretasi, kritikan atau saran. Tim pengusul memberikan masukan terhadap kekurangan yang terjadi agar pelaksanaan berikutnya menjadi lebih baik.

Pelaksanaan program pendampingan ini dievaluasi dengan memberikan tes kepada peserta untuk mengukur pemahaman peserta terkait pengembangan instrument penilaian kompetensi minimum. Instrumen yang digunakan untuk mengukur tingkat pengetahuan adalah kuesioner dengan pertanyaan terbuka sejumlah 15 pertanyaan. Kuesioner tersebut terdiri dari pertanyaan mengenai hakikat assessment kompetensi minimum (AKM), komponen-komponennya dan cara mengembangkan soal jenis assessment kompetensi minimum (AKM) berorientasi PISA. Pada analisis deskriptif, tingkat pengetahuan dibagi ke dalam kategori baik (jawaban benar >75), cukup (jawaban benar 50-75) dan kurang (jawaban benar $>50$ ). Data tingkat pengetahuan di sini menggambarkan penguasaan guru terhadap pengembangan penilaian berbasis assessment kompetensi minimum (AKM).

\section{HASIL DAN PEMBAHASAN}

Kegiatan pengabdian kepada masyarakat ini telah dilaksanakan selama 3 hari yakni pada tanggal 17 sampai dengan 19 Februari 2021. Kegiatan ini diawali dengan observasi sekolah sasaran secara online berdasarkan data-data yang terdapat pada Badan Pusat Statistik Provinsi Jawa Barat, Dapodik Sekolah Dasar di Kabupaten Bogor. Kegiatan pengabdian masyarakat ini diadakan secara online dengan mengusung tema "Penguatan Kompetensi Guru Sekolah Dasar Pada Era New Normal”. Berlakunya system new normal, sampai saat ini 
sekolah belum dapat melayani peserta didik secara langsung termasuk sekolah dasar. Pembelajaran yang biasanya dilaksanakan secara tatap muka beralih menjadi menjadi pembelajaran jarak jauh. Tentunya kondisi ini menimbulkan permasalahan di kalangan para praktisi Pendidikan dimana mereka harus memberikan suatu pembelajaran yang bermakna kepada peserta didik khususnya pada jenjang usia SD agar mereka tetap dapat belajar dengan efektif dan menyenangkan walaupun secara digital.

Kegiatan pengabdian masyarakat ini dilaksanakan dengan menggunakan aplikasi zoom meeting. Pada pelaksanaannya, tim pengusul dan peserta dibagi menjadi 3 kelompok room pada zoom. Tim pengusul melakukan pemaparan mengenai pemahaman guru terkait assesment kompetensi minimum (AKM) di hari pertama, pendampingan di hari kedua, dan evaluasi di hari ke tiga.

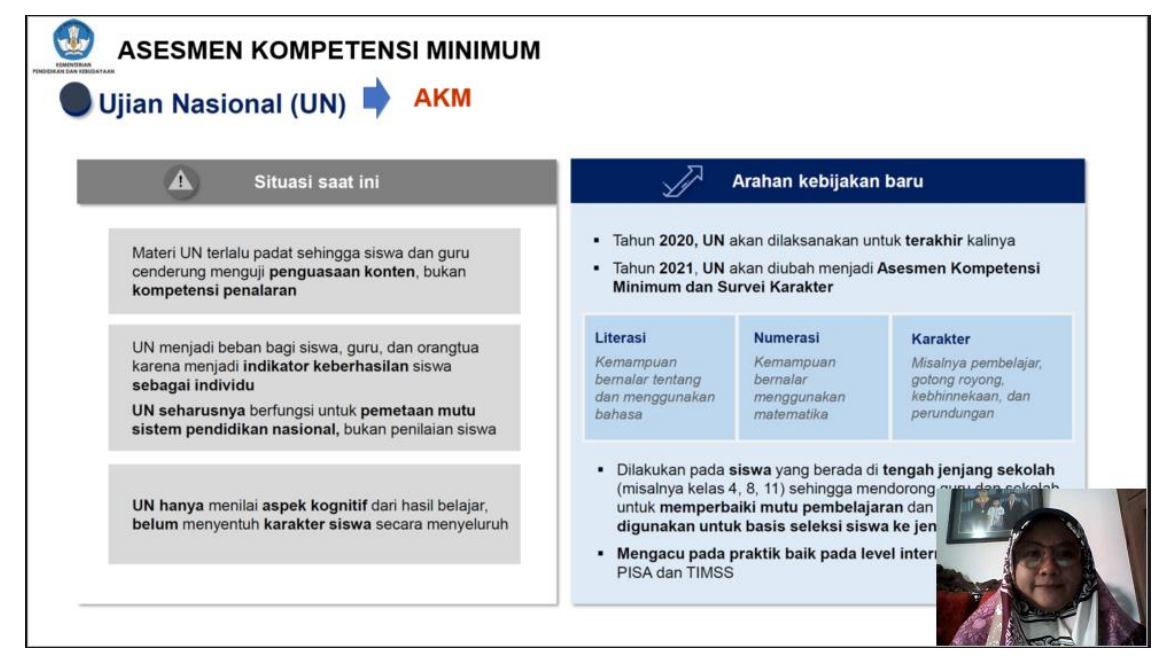

Gambar 1. Tim sedang memaparkan materi

Berdasarkan hasil pelaksanaan kegiatan pengabdian masyarakat, sebanyak $88 \%$ guru memperoleh skor 85 dengan kategori (pengetahuan baik). Adapun hasil tes pengetahuan dari para peserta pengabdian masyarakat adalah sebagai berikut :

Tabel 1. Tingkat Pengetahuan Peserta

\begin{tabular}{lcccc}
\hline \multirow{2}{*}{ Tingkat Pengetahuan } & \multicolumn{2}{c}{ Pretest } & \multicolumn{2}{c}{ Posttest } \\
\cline { 2 - 5 } & $\begin{array}{c}\text { Jumlah } \\
\text { (orang) }\end{array}$ & Persentase & $\begin{array}{c}\text { Jumlah } \\
\text { (orang) }\end{array}$ & Persentase \\
\hline Baik & 46 & 43.0 & 78 & 72.9 \\
Cukup & 38 & 35.5 & 18 & 16.8 \\
Kurang & 23 & 21.5 & 11 & 10.3 \\
\hline Jumlah & 107 & 100 & 107 & 100 \\
\hline
\end{tabular}


Tabel di atas menggambarkan bahwa tingkat pengetahuan peserta setelah diadakan kegiatan pendampingan memiliki persentase yang meningkat. Hal ini menunjukkan bahwa adanya kegiatan pengabdian masyarakat ini sangat berperan dalam menunjang kapasitas guru untuk meningkatkan kualitas pembelajaran. Dalam kurikulum 2013, penilaian terhadap pembelajaran harus mencakup aspek yang dimiliki siswa baik secara kognitif, afektif, dan psikomotornya. Penilaian adalah istilah yang luas didefinisikan sebagai proses untuk memperoleh informasi yang digunakan untuk membuat keputusan terhadap siswa, kurikulum, program dan sekolah, dan kebijakan pendidikan (Villarroel et al., 2017; Wiggins, 1990). Penilaian merupakan bagian integral dari suatu pembelajaran karena itu perlu dilaksanakan secara terpadu.

Assesmen kompetensi minimum (AKM) merupakan penilaian kompetensi mendasar yang diperlukan oleh semua murid untuk mampu mengembangkan kapasitas diri dan berpartisipasi positif pada masyarakat. Terdapat dua kompetensi mendasar yang diukur dalam assessment kompetensi minimum (AKM) adalah literasi membaca dan literasi matematika (numerasi). Pada literasi ini, kompetensi yang dinilai mencakup: keterampilan berpikir logis-sistematis keterampilan bernalar menggunakan konsep serta pengetahuan yang telah dipelajari keterampilan memilah serta mengolah informasi assessment kompetensi minimum (AKM) menyajikan masalah-masalah dengan beragam konteks yang diharapkan mampu diselesaikan oleh murid menggunakan kompetensi literasi membaca dan numerasi yang dimilikinya (Thien, 2016). PISA (Programme for International Student Assessment) adalah studi internasional tentang prestasi literasi membaca, matematika, dan sains siswa sekolah berusia 15 tahun. Penyelenggara studi adalah OECD (Organisation for Economic Cooperation and Development) beserta konsorsium internasional yang membidangi masalah Sampling, Instrumen, Data, Pelaporan, dan secretariat (Fathani, 2016; Lemke et al., 2004; OECD, 2019).

PISA merupakan studi yang diselenggarakan setiap tiga tahun sekali, yaitu pada tahun 2000, 2003, 2006, 2009, 2012 dan seterusnya. Indonesia mulai sepenuhnya berpartisipasi sejak tahun 2001. Pada setiap siklus, terdapat 1 domain major sebagai fokus studi. PISA tidak hanya memberikan informasi tentang benchmark Internasional tetapi juga informasi mengenai kelemahan serta kekuatan siswa beserta faktor-faktor yang mempengaruhinya. AKM dimaksudkan PISA untuk mengukur kompetensi secara mendalam, tidak sekadar penguasaan konten. Literasi membaca didefinisikan sebagai kemampuan untuk memahami, menggunakan, mengevaluasi, dan merefleksikan berbagai jenis teks tertulis (Fong Peng, 
2015). Tentu untuk mengembangkan kapasitas individu sebagai warga Indonesia dan warga dunia, juga untuk dapat berkontribusi secara produktif kepada masyarakat. Numerasi adalah kemampuan berpikir menggunakan konsep, prosedur, fakta, dan alat matematika (Hasnawati, 2016; Thien, 2016).

Dengan demikian, literasi dalam penilaian berbasis assessment kompetensi minimum (AKM) ini bukan hanya kemampuan membaca dan memahami angka saja, tetapi kemampuan menganalisis suatu bacaan, dan memahami konsep di balik tulisan tersebut. Jadi bukan berdasarkan mata pelajaran dan penguasaan materi melainkan kompetensi minimum atau kompetensi dasar yang dibutuhkan siswa untuk bisa belajar.

\section{KESIMPULAN}

Berdasarkan hasil kegiatan pengabdian masyarakat, presentase skor peserta telah meningkat antara pretest dan posttest yaitu dari 43,0 \% meningkat menjadi 72,9\%. Hal ini menggambarkan bahwa kegiatan pendampingan dapat dikatakan berhasil. Adapun pengembangan instrument soal berbasis assessment kompetensi minimum (AKM) akan sangat bermanfaat lagi jika diimbaskan pada sekolah-sekolah lain dalam ruang lingkup yang lebih luas. Adanya kegiatan ini dapat membuat guru melahirkan pemikiran dan gagasan yang kritis dan inovatif sehingga menghasilkan kebaruan untuk meningkatkan kualitas pembelajaran.

\section{UCAPAN TERIMAKASIH}

Kegiatan pengabdian masyarakat ini diadakan berkat kerja sama dengan mitra yaitu Dinas Pendidikan Kabupaten Bogor. Kami segenap tim pengusul dalam kegiatan ini mengucapkan banyak terimakasih pada segenap jajaran Dinas Pendidikan Kabupaten Bogor yang telah berpartisipasi dan ikut mendukung terlaksananya kegiatan pengabdian masyarakat ini.

\section{DAFTAR PUSTAKA}

Alfian, A., Aminah, N. S., \& Sarwanto. (2015). Authentic Assessment Berbasis Scientific Approach Sebagai Implementasi Kurikulum 2013 DI SMP Kelas VII Pada Materi Suhu Dan Perubahannya. Jurnal Inkuiri, 4(3).

Azim, S., \& Khan, M. (2012). Authentic assessment: An instructional tool to enhance students learning. Academic Research International, 2(3), 314-320. http://ecommons.aku.edu/pakistan_ied_pdcc

Baldi, S., Jin, Y., Skemer, M., Green, P. J., \& Herget, D. (2007). Highlights From PISA 2006: Performance of U.S. 15-Year-Old Students in Science and Mathematics Literacy in an International Context. Ies, 1-9.

Charoenchai, C., Phuseeorn, S., \& Phengsawat, W. (2015). Teachers' development model to authentic assessment by empowerment evaluation approach. 10(17), 2524-2530. https://doi.org/10.5897/ERR2015.2243

de Sam Lazaro, S. L. (2017). The Importance of Authentic Assessments in Eligibility Determination for Infants and Toddlers. Journal of Early Intervention, 39(2), 88-105. 


\section{https://doi.org/10.1177/1053815116689061}

Ermawati, Siti., \& Hidayat, T. (2017). Penilaian autentik dan relevansinya dengan kualitas hasil pembelajaran (persepsi dosen dan mahasiswa ikip pgri bojonegoro). Jurnal Pendidikan Ilmu Sosial, 27(1), 92-103.

Fathani, A. H. (2016). Rahmah Johar. "Domain Soal PISA untuk Literasi matematikaa". Jurnal Peluang, Volume 1, Nomor 1, Oktober 2012. 136. Jurnal EduSains, 4(2), 136-150.

Fitriani. (2017). | 164 Getsempena English Education Journal (GEEJ) Vol.4 No.2 Novemver 2017. Implementing Authentic Assessment of Curriculum 2013: Teacher'S Problems and Solusions, 4(2), 164-171.

Fong Peng, C. (2015). Perlaksanaan Program Literasi dan Numrasi (LINUS). Malay Language Education Journal - MyLEJ.

Hasnawati. (2016). Description Of Mathematics Literacy Ability of Students First Secondary School State 15 Kendari Based On Content, Context, Materials and Process. International Journal of Education and Research, 4(4), 185-196.

Hodgman, M. R. (2014). Using Authentic Assessments to Better Facilitate Teaching and Learning: The Case for Student Portfolios. Journal of Studies in Education, 4(3), 59. https://doi.org/10.5296/jse.v4i3.6149

Holliday, W., Dance, B., Davis, E., Hedrich, A., \& Lundstrom, K. (2015). An Information Literacy Snapshot: Authentic Assessment across the Curriculum. https://doi.org/10.5860/crl.76.2.170

James, L. T., \& Casidy, R. (2018). Authentic assessment in business education: its effects on student satisfaction and promoting behaviour. Studies in Higher Education, 43(3), 401-415. https://doi.org/10.1080/03075079.2016.1165659

Kaj, M. P. K. (2020). Asesmen Kompetensi Minimum. September, 1-4.

Kartowagiran, B., \& Jaedun, A. (2016). MODEL ASESMEN AUTENTIK UNTUK MENILAI HASIL BELAJAR SISWA SEKOLAH MENENGAH PERTAMA (SMP): IMPLEMENTASI ASESMEN AUTENTIK DI SMP. Jurnal Penelitian Dan Evaluasi Pendidikan. https://doi.org/10.21831/pep.v20i2.10063

Larkin, T. L. (2014). The Student Conference: A Model of Authentic Assessment. International Journal of Engineering Pedagogy (IJEP), 4(2), 36. https://doi.org/10.3991/ijep.v4i2.3445

Lebrun, M. (2017). Healthy Children, Healthy Minds: Creating a Brighter Future. IAFOR Journal of Education, 3(2), 110-124. https://doi.org/10.22492/ije.3.2.07

Lemke, M., Sen, A., Pahlke, E., Partelow, L., Miller, D., Williams, T., Kastberg, D., \& Jocelyn, L. (2004). International Outcomes of Learning in Mathematics Literacy and Problem Solving: PISA 2003 Results From the U.S. Perspective. Highlights. NCES 2005-003. US Department of Education. http://eric.ed.gov/?id=ED484183

Noor, M., Yusoff, N. M., \& Noor, M. (2016). Improving Process Writing with the Use Authentic Assessment. 5(3), 200-204.

OECD. (2019). PISA 2018 insights and interpretations. OECD Publishing, 64. https://www.oecd.org/pisa/PISA 2018 Insights and Interpretations FINAL PDF.pdf

Penelitian, J., Pendidikan, E., Model, P., Kompetensi, A., \& Smk, S. (2013). Pengembagan Model Asesmen Kompetensi Siswa SMK dalam Konteks Pembelajaran Berbasis Kerja di Industri. Jurnal Penelitian Dan Evaluasi Pendidikan, 14(2), 246-268. https://doi.org/10.21831/pep.v14i2.1081

Pratiwi, I. (2019). Efek Program Pisa Terhadap Kurikulum Di Indonesia. Jurnal Pendidikan Dan Kebudayaan, 4(1), 51. https://doi.org/10.24832/jpnk.v4i1.1157

Quint, J., \& Condliffe, B. (2018). Project-Based Learning: A Promising Approach to Improving 
Student Outcomes. Issue Focus. Mdrc, January. www.mdrc.org

Steele, P., Johnston, E., Lawlor, A., Smith, C., \& Lamppa, S. (2019). Arts-Based Instructional and Curricular Strategies for Working With Virtual Educational Applications. Journal of Educational Technology Systems, 47(3), 411-432. https://doi.org/10.1177/0047239518803286

Susani, R. G. (2018). THE IMPLEMENTATION OF AUTHENTIC ASSESSMENT Indonesian Language Education and Literature Study Program. 11(1), 87-92.

Thien, L. M. (2016). Malaysian Students' Performance in Mathematics Literacy in PISA from Gender and Socioeconomic Status Perspectives. Asia-Pacific Education Researcher, 25(4), 657-666. https://doi.org/10.1007/s40299-016-0295-0

Villarroel, V., Bloxham, S., Bruna, D., Bruna, C., \& Herrera-seda, C. (2017). Assessment \& Evaluation in Higher Education Authentic assessment: creating a blueprint for course design. Assessment \& Evaluation in Higher Education, 2938(December), 1-14. https://doi.org/10.1080/02602938.2017.1412396

Widana, I. W. (2017). HIGHER ORDER THINKING SKILLS ASSESSMENT ( HOTS ) I Wayan Widana. 3(1), 32-44.

Wiggins, G. (1990). The case for authentic assessment. - practical assessment, research \& evaluation. Practical Assessment, Research, \& Evaluation, 2(2), 1-3. http://pareonline.net/getvn.asp? $\mathrm{v}=2 \& \mathrm{n}=2$ 